\title{
A closer look at Ilsaac Oluwole Delano's A Dictionary of Yoruba Monosyllabic Verbs
}

Toyin Falola

University of Texas at Austin

toyinfalola@austin.utexas.edu

Michael Oladejo Afolayan

M\&P Educational Consulting International

Osogbo, Nigeria and Springfield, Illinois

mafolayan@yahoo.com

\section{Part A \\ Introduction}

What follows is a revised version of our introductory segment to Isaac O. Delano's A Dictionary of Yoruba Monosyllabic Verbs. In it, we provided a historical narrative of the emergence of the dictionary as the main tool for lexicographers. We also attempted to construct the historical assumptions of what could be construed as the value of a dictionary. We spoke to the utility of the dictionary and lamented over its obvious underutilization. We then went ahead to provide the various types of dictionaries and their value as a modern research tool. With the introduction, and having established the significance of a dictionary, we looked specifically at Delano's pioneering work of the monosyllabic dictionary specifically.

\section{A Historic View of the Dictionary}

Before the modern formation of what is known as the dictionary and its development by lexicographers, its earliest conception goes as far back as the Sumerian time in history, as bilingual wordlists in cuneiform tablets. The

1 Originally published in Michael O. Afọlayan eds. Isaac O. Delanọ A Dictionary of Yoruba Monosyllabic Verbs Edited with an Introduction. Pan-African University Press, 2020. 
ambiguity of defining a dictionary is as ironical as its functions. After deconstructing the various definitions of a dictionary, Bergenholt proposes that a dictionary is a "Lexicographic reference work containing dictionary articles related to individual topics or elements of language, and possibly several outer texts as well, which can be consulted if someone needs assistance with text reception, text production or translation or would simply like to know more about a word, part of a word or a combination of words."2 Nevertheless, his definition is as wanting as those he criticized, which highlights the problem that arises from attempts to generate an absolute definition of the term.

On the one hand, dictionaries are used to provide clear definition of a word or terminology, and on the other hand, they do so by reverting to other terms to evoke this definition. This circularity of definition often leads to an endless cycle in pursuit of meaning, especially for foreign language learners, and highlights the descriptive and prescriptive undertones of dictionaries (rather than a supposed absolute definition). However, dictionaries are lexicographic reference books defining the corpus of available words in a language, region or field. Usually arranged in alphabetic order for easy usage, they contain essential components about the formation and appropriate usage of a word. Dictionary-also referred to as wordbook-vocabulary and lexicon are significant towards the documentation, standardization, acquisition and proper usage of a language.

Despite their significance, dictionaries are underutilized, and even discouraged by some scholars of language as unhelpful towards the adequate acquisition and enhancement of language. While the relations and relevance of dictionaries to language acquisition or researches is not an end to itself, hence dispensable, the reluctance to use dictionaries for this purpose has been identified by Carstens as a result of the inappropriateness of the dictionary or/and the lack of good dictionary-using skills on the part of the language learner or researcher. ${ }^{3}$

Paul Nation ${ }^{4}$ suggests that a good dictionary should contain a sufficient amount of words, be clear and easy to comprehend, provide information about the grammar and collocation of words, provide adequate information about the spelling and pronunciation of words, and provide information about related words and multiple definition and usage of a word as well as the limitations of such entries. At best, the definition of a dictionary is as descriptive and prescriptive as its function.

\footnotetext{
2 Henning Bergenholt. “What is a Dictionary?" Lexikos 22 (2012): 30.

3 Adelia Carstens. "Language Teaching and Dictionary Use: An Overview." Lexikos 5 (1995): 106.

4 Nation, Paul. Teaching Vocabulary (Strategies and Techniques). Boston: Heinie, 2008 .
} 


\section{Types of Dictionaries and Their Significance}

As much as there are numerous types and classifications of dictionaries ${ }^{5}$, they can be simply grouped into three major ones based on purpose and form: Language Dictionaries, Subject-specific Dictionaries, and Electronic/Online Dictionaries.

(1) Language Dictionary: The dictionaries under this category are language-specific as they provide short and precise definitions of words in a language. Sometimes, word class, pronunciation, syllabication, accentuation, etymology, and their usage are cited as examples. This type of dictionary is also referred to as a general dictionary, and can be further divided into the following subtypes:

a. Monolingual Dictionary: This is perhaps the most common type of available dictionaries as they provide multiple and detailed but concise information about a word in a specific language. Examples of learner's dictionaries include the Longman Dictionary of Contemporary English, Macmillan English Dictionary, Cambridge International Dictionary of English, Oxford English Dictionary (OED), and the Miriam-Webster Dictionary etc.

b. Bilingual and Multilingual Dictionary: This type of dictionary provides translation or side-by-side information about words in two languages, usually for language learning purposes. Unlike the monolingual dictionary, bilingual dictionaries give limited information as their ultimate function is to provide parallel or synonymous words in two languages (usually from a user's native language to a second or foreign language). Alhaisoni notes that "the use of bilingual dictionaries is effective because they provide ready translation equivalents for common words and exact translation equivalents for institutional technical and scientific terms." Examples of bilingual dictionaries include The Megiddo Modern Dictionary, Oxford English-Hebrew Dictionary, Collins and Robert French-English English-French Dictionary etc.

c. Learner's Dictionary: This type of dictionary can be either monolingual or bilingual, but with a simplified definition and components, usually to enhance its usage by a less-proficient language speaker, especially foreign learners. Although sometimes limited in entries, the dictions of learner's

5 Li and Zhon (2001) offers an expansive model dictionary classification along the variables of size, form/medium, scope of words, language, content/subject, historical period and arrangement. (quoted in Win Jenpattarakul. "Optimizing the Advantages of Monolingual Dictionary Utilization by Thai EFL Students." Mediterranean Journal of Social Sciences Vol. 3.11, (2012): 146.)

6 Eid Alhaisoni. "EFL Teachers' and Students' Perceptions of Dictionary Use and Preferences.” International Journal of Linguistics Vol. 8, No. 6 (2016): 33. 
dictionaries are simplified and easy to comprehend. Additionally, the scope of this dictionary is made suitable and specific to a group of people or region as it puts into consideration their background to enhance the accessibility and acquisition of the new language by contextualizing the definitions of available words Examples of learner's dictionaries include the Oxford Advanced Learner's Dictionary, Passport English Hebrew Learner's Dictionary, Macmillan English Dictionary for Advanced Learners, Cambridge Advanced Learner's Dictionary, Collins Cobuild English Language Dictionary etc.

(2) Subject-Specific Dictionary: Also referred to as technical or specialized dictionaries, this type of dictionary is used to give precise definition of terminologies specific to a subject, field or area of life. Unlike language dictionaries, they are very limited in scope and function to the particular field they've been designed for, and their usages are a bit more technical. They are used by in-field professionals or specialists to obtain quick and short information about a term. The scope of subject-specific dictionaries vary from multiple areas of a subject, a single area of a subject to a sub-area of a subject. The components of subject-specific dictionaries are usually referred to as terms rather than words that obtain in general dictionaries, as they connote usage specificity. Examples of subject-specific dictionaries are The Concise Oxford Dictionary of Literary Terms, Oxford Diction of World Religions, Oxford Medical Dictionary, Black's Law Dictionary etc. Also, the Encyclopedia Dictionary and Rhyming Dictionary can also be classified as subject-specific dictionaries.

(3) Electronic Dictionary: Unlike the aforementioned types of dictionaries, online or electronic dictionaries are manifestations of the dictionary in digital form, either online (through the internet) or as independent applications that are accessible on phones, tablets and computers. Compared to paper dictionaries, electronic dictionaries have been ascertained to be more helpful to foreign language learners in enhancing reading comprehension and vocabulary acquisition. ${ }^{7}$ A not-farfetched reason is not only because there is the strong intervention of digital technology in our daily activities, but because electronic dictionaries are more accessible, easily navigated, customizable, constantly updated and innovative with activities and additional features (e.g. quizzes, illustrations, flashcards, new word notifications, a-word-a-day learning methods etc.) that stimulate an

7 Abdulaziz Ibraheem Fageeh. "Effects of Using the Online Dictionary for Etymological Analysis on Vocabulary Development in EFL College Students." Theory and Practice in Language Studies Vol. 4, No. 5 (2014): 883. 
effortless and gradual language enhancement. The easy navigation that characterizes electronic dictionaries eliminates or reduces to a bearable extent the meaning circularity in the definition of an entry. Also, due to the absence of space limitations, electronic dictionaries- especially online-are more elaborate than paper dictionaries, as they provide more information about an entry. For instance, electronic dictionaries contain more illustrations and links that afford the learner more knowledge about a word/term. As medium is the major difference between paper and electronic dictionaries, most dictionaries available in paper forms are now available as electronic dictionaries.

\section{Significance of the Dictionary}

1. Efficient use of the dictionary helps to learn appropriate word usage, definition and components, especially with words that have multiple entries, definitions and use. Alongside the definition and usage, other essential components of a word like word class, pronunciation, spelling, meaning relation (antonyms and synonyms) and idiomatic expressions associated with a word are sufficiently described. With the coinage of new words, the dictionary plays a significant role in their documentation, preservation, presentation, acquisition and utilization.

2. As the most significant and successful book about language ${ }^{8}$, a dictionary serves as the basics of acquiring a new language. As a device of enhancing language learning and proficiency, bilingual and multilingual dictionaries perform translation purposes by providing alternative words for a target word from a language to another. While this process is often fairly accurate, it aids independent and flexible language learning which strengthens the vocabulary acquisition of the learner. With the advent of electronic dictionaries, the translation of a language from one to another (or many) has become easier and more accurate, as the capabilities of these dictionaries transcend the lexical level to include more complex syntactic structures as sentences, paragraphs and discourses. Illustrations are innovative strategies introduced into dictionaries to help learners better comprehend and make real-life connections between a new word and its meaning or referent. Also, more innovate methods embedded in electronic dictionaries like the transliteration of a language from a format to (preferably) another, maybe from image/audio to text or vice-versa.

3. Dictionaries serve as reference guides for researchers. The dictionary provides a wealth of information about words and terminologies, and due

8 Robert Ilson. "Introduction," in Dictionaries, Lexicography and Language Learning, ed. Robert Ilson. (Oxford: Pergamon Press Ltd., 1985) 1. 
to a reasonable amount of validity that has been ascribed to it, it has assumed a state of relevance, especially among language researchers. In the same vein, subject-specific or specialized dictionaries afford in-field professionals quick knowledge about certain terminology. Usually, this short but precise information are the first step to the more elaborate process of research. Accordingly, Cortés notes that "dictionaries of technical terms can provide definitions when the context is not enough to get the meaning of scientific terms."

4. The component of the dictionary detailing the first usage and origin of a word helps to record word changes and development. In highlighting the etymologies of lexicons in a language, they help to study the historical transformation of a language.

5. The proper use of the dictionary facilitates and contributes to the acquisition of general reference skills which aid researches, self-study and self-education. The systematic structure to the typology of a dictionary enhances the development of well-coordinated research skills in a dictionary user who has acquired certain "skills based on knowledge of the structural organization of dictionaries." 10 These skills range from the ability to identify a problem, source of solution (the example of dictionary typology appropriateness) and the most appropriate solution to interpretation skills, and the ability to minimize the disruptive tendency of conducting a dictionary while reading or engaged in research activities. In short, the ability to adequately conduct a dictionary is a reduction of a good research, reading and comprehension skills.

6. As a reference guide, dictionaries perform language standardization and policy functions by giving credence to the acceptable usage of a language, generally or in relation to a specific region. The lack of proper documentation of a language leads to diverse manifestations of the language, which can neither be classified as absolutely wrong or right, deriding the language of uniformity, clarity and standardization. But dictionaries aid the process of language documentation, preservation and development, which eventually contributes to its standardization. As a reference guide, it consolidates policies that promotes language enhancement. The publication of Samuel Johnson's A Dictionary of the English Language in England in 1755 contributed immensely to the standardization of the English language and the development of what is today known as Modern English.

9 Cortés, Ximena. "Using the Dictionary for Improving Adolescents' Reading Comprehension of Short Scientific Texts." PROFILE Vol. 15, No. 2 (2013): 13.

10 Adelia Carstens. "Language Teaching and Dictionary Use: An Overview." Lexikos 5 (1995): 110. 
7. Extensively, dictionaries preserve and present a culture. As a compendium of words available in a language, dictionaries help to introduce a language and its worldview to its readers as they acquire the lexico-semiotic understanding of such culture. Simultaneously, by presenting the worldview to a wider audience, the dictionary is preserving such cultures in time.

8. Similarly, dictionaries are significant historical texts. Aside from documenting and preserving the word entries available in a language across time, the etymology or being of these words are historical signifiers through which a period in time can be understood, through the narratives woven around its words and use of language. Also, in tracing the etymology of words, biographical details of places, people, events and things are given for clear elucidation.

9. Beyond serving as a word reference text, dictionaries contain factual information about a place, as well as lists of weights, measures, symbols and so on. This additional information places the dictionary as an irrefutable source of certain general information, aside from defining a word or terminology. Common examples of such general information includes abbreviations/acronyms, grammatical rules, the brief history of a language and national currencies, even style guides and information on Prime Ministers and Governor Generals as evident in the Canadian Oxford Dictionary. Electronic dictionaries go beyond the space limitation of paper dictionaries to include extensive information (through links) beyond the scope of the dictionary.

\section{PART B \\ Delano's A Dictionary of Yoruba Monosyllabic Verbs, Sixth Edition}

Above, we have established the significance of a dictionary. The pedagogical value of a dictionary as a reference guide and the go-to document for advanced researchers, as well as for the most rudimentary learners, is unquantifiable. It has always been a part of the learning process. Yet, it is not tautological to say a dictionary is a dictionary. It is a conglomeration of words within a formal text, and there is not much else to say about it; it becomes a metalingual task when words have to be used to describe or explain words. Therefore, more would be addressed in this segment about related matters, rather than focusing on the dictionary of Delano per se. However, suffice to say that the work of compiling the dictionary of any language is a daunting one. It is particularly difficult when there is no overwhelming standing tradition for such lexicographic work in the language. 
Relatively speaking, writing a dictionary in most Western languages, for example, should not be a particularly tasking experience because there has been a long-standing tradition of publishing dictionaries in those languages, and there are many dictionaries already published in which the lexicographer could lean on for guidance in organizing the text and even in the choice of lexical items to be entered into the proposed work. In many less-documented traditions, it could be excruciatingly difficult because in the attempt to put together a viable dictionary, the author may have to start almost from scratch. In worst case scenarios, the author may even have to start the project by collecting words directly from speakers of the language in question.

As of Delano's time, only limited documentations had been made of the Yoruba language in the form of dictionaries. R.C. Abraham and Samuel Ajayi Crowther (in concert with the Church Missionary Society and Oxford University Press) did appreciable works that were published and are still in circulation; we will touch on these two efforts momentarily. Other than these two, not much is known of other efforts at producing Yoruba dictionaries of any sort prior to that of Delano. Even since Delano's seminal work, efforts have been, at the very best, minimal. In the mid-1970s, for example, Professor Adebisi Afolayan, through an initiative supported by UNESCO, led the Yoruba Society of Nigeria in a Yoruba dictionary project. In the process, a collection of words in the language was initiated. The effort did not continue and consequently did not lead to the publication of any of the materials. Indeed, apart from the known work of O. B. Yai ${ }^{11}$ and the effort of L. O. Adewole $^{12}$, we are not aware of other serious efforts to publish a Yoruba dictionary. This underscores the strenuous task associated with the writing of Yoruba dictionaries.

\section{Works Predating Delano's}

As noted earlier, the two major bilingual dictionaries that are still in circulation in the Yoruba language today are 1) the 1950 edition of A Dictionary of the Yoruba Language (reprinted in 1980) - a collaborative project of the Church Missionary Society (CMS) and Oxford University Press (OUP); and 2) R. C. Abraham's Dictionary of Modern Yoruba. In the "Publisher's Note" to CMS/OUP's A Dictionary of the Yoruba Language, we read:

Canon C. W. Wakeman's Introduction to the first edition of this Dictionary records that 'the first Dictionary of the Yoruba language was published in

11 O. B. Yai, Yoruba-English/English-Yoruba Concise Dictionary (Hippocrene Concise Dictionaries) (English and Yoruba Edition), Hippocrene Books, 1996.

12 L. O. Adewole of Obafemi Awolowo University shared with me the transcript of his solo work on the Yoruba Dictionary. Though the work is still in progress, it is a promising project in light of the comprehensive nature of the said dictionary. 
the year 1843, compiled by Samuel (afterwards Bishop) Crowther. This was greatly altered and considerably enlarged for a new edition in 1852. For many years this book was the standard work on the Yoruba language. . In 1911 an English-Yoruba Dictionary was published under the general editorship of the Rev. E. J. Sowande, but this was only intended to meet immediate needs, and, like the older book, is out of print. ${ }^{13}$

There is no doubt that efforts in the making of Yoruba dictionaries had been on-going for an appreciably long time. The current edition, therefore, is an improvement on the work of Bishop Samuel Ajayi Crowther, but the initial work has metamorphosed into various editions and impressions. The very first publication of it was done by the Church Missionary Society in 1913. This is a unique dictionary in its publishing format, which must have been designed to serve a totally different purpose and population, especially when compared to the one by Delano. The first part of the dictionary is a selection of a list of words in the English language that were translated to the Yoruba language, akin to a glossary or word guide for travelers. The second part is a selection of a list of words in the Yoruba language, which were translated to the English language. Apparently, it could be inferred that the project was probably embarked upon more for the service of missionaries and probably the colonial administrators, rather than for a work intended to benefit researchers or writers of the Yoruba language. By virtue of its presumed intended purpose, this particular dictionary is understandably the simpler of the duo. While R. C. Abraham's work involves elaborate annotations of the items entered, the one by the CMS/OUP is a whole lot simpler; it is, in essence, more of a thesaurus than a standard dictionary. It defines concepts but hardly annotates or exemplifies items being defined. It is brief. Take for example, in the entry "gbà," the CMS//OUP dictionary provides a ten-word description of the word. R. C. Abraham's dictionary, on the other hand, has an entry that includes five pages of information on the same lexical item. In quantity and quality, therefore, the CMS/OUP work is less than that of R. C. Abraham's Dictionary of Modern Yoruba. This does not diminish the value of the publication but explains its purpose.

The best known and by far most enduring of Yoruba bilingual dictionaries is the one put together by R. C. Abraham, titled Dictionary of Modern Yoruba. This has been the most comprehensive and most utilized of the known Yoruba dictionaries of all times. Indeed, of all dictionaries in African languages done by Abraham, the one in Yoruba is said to be the most known and utilized. It

13 See Publisher's Note, A Dictionary of the Yoruba Language. Ibadan: Oxford University Press, 1950 (unpaged) 
is an assemblage of words carefully compiled alphabetically. The author, Roy Clive Abraham, was a foremost linguist described as "a key figure in African language scholarship during the twentieth century."14 The archive that honors his works and lifetime achievements is kept at the School of Oriental and African Studies of the University of London. ${ }^{15}$ Like the likes of Ulli Beir, R. C. Abraham would always be remembered as one of those foreign visitors to the Yoruba community of old, but, in the words of Wole Soyinka, "becoming its passionate expositor, not fulsomely, but critically, with a love that surpassed that of many who were born into it."16

R. C. Abraham's Dictionary of Modern Yoruba has become the classical document for Yoruba lexicography. It is the most comprehensive, almost encyclopedic compilation of information relating to the Yoruba language and literature. In the first segment of the work, Abraham provides an all-inclusive information about the tones of the language. In it, he talks about the various levels of tone efficacy and how tone is the primary determinant of meaning in the language. Following the discourse on tones, Abraham moves to the phonology of the language. Here, he delves into the points and manners of articulation and nasal implications of certain sounds in the language. The grammar of the language would occupy the next few pages in the dictionary. There, he identifies 21 different tenses in the language, and proffers a discussion of the phenomena of elision and contraction, capping off the segment with a discussion and exemplification of the complexity of the Yoruba numerals. The author acknowledges several works he consulted for the project including 149 books and 21 archival materials. The work completed with a dedicated section on "Addenda." This includes, in the words of the author, ". . .words which became known to me after the text of the Dictionary was completed and therefore could not be inserted. However, wherever such additional word has to be inserted, the (certain) sign appears in the alphabetical position where such additional word belongs and whenever this sign is seen, the user the user of the Dictionary should refer back to the present list of List of Addenda." 17

No doubt, Abraham's Dictionary of Modern Yoruba is both a dictionary in its own right, and a book of grammar, culture and the society. Indeed, it could be seen as a handbook of Yoruba language and civilization rather than just a dictionary. Underscoring this point, the author puts it succinctly:

14 See R. G. Armstrong, 'Roy Clive Abraham, 1890-1963', Journal of West African Languages, $1 / 1$ (1964), 49-53

15 See http://www.soas.ac.uk/library/archives/.

16 See Wole Soyinka in Wole Ogundele's Gone to Join Obatala: Tributes on Ulli Beier, 2012, p. 57.

17 See page 691. 
This dictionary covers every aspect of Yoruba civilization: It therefore includes countless idioms, current phrases, proverbs and riddles. Further, I have fully explained the historical religious, and ethnological facts which form the background of the vocabulary and without which mere knowledge of lexicology would be meaningless. The needs of the student of nature have been catered for from thee living organisms by detailed description of plants, trees, flowers, animals, insects and reptiles, these being illustrated by four hundred pictures. ${ }^{18}$

The lexicographical part of the book is the main thrust of the work. It is comprised of the systematic organization of words in the alphabetical order. From monosyllabic to multisyllabic lexical items, the work provides an entry of thousands of Yoruba words that come with annotations and illustrations. It is no gainsaying that any reference to a modern and viable dictionary in the Yoruba language cannot be complete without a definite reference to R. C. Abraham's Dictionary of Modern Yoruba, first published in 1946 by Hodder and Stoughton Educational, a division of Hodder and Stoughton Ltd.

\section{A Critique of Abraham's Dictionary of Modern Yoruba}

The work of a dictionary is, on one hand, technical. On the other hand, it is instinctual. Therefore, both intellectual and intuitive knowledge of the language are essential parameters for doing a good job of lexicography. To this end, dictionary drafting is not an easy task for anyone, let alone non-natives. In fact, according to Kemper, who herself is a world renown lexicographer, one of the two key prima facie qualifications of a dictionary writer at her organization, Merriam-Webster, is being a native speaker of the English language, since her organizer is famous for its dictionary. She writes:

At Merriam-Webster, there are only two formal requirements to be a lexicographer: You must have a degree in any field from an accredited fouryear college or university, and you must be a native speaker of English. ${ }^{19}$

While one might think a knowledge-based academic degree in one of the branches of language studies (linguistics, especially) would be the main requirement for being a lexicographer, it is apparent that being a native speaker

18 See R.C. Abraham's Dictionary of Modern Yoruba, p. iii.

19 Kory Stamper, "I'm the Person Who Writes the Dictionary-This Is What My Job Is Like" in Readers Digest 
of the language being complied is more of a necessity than a superficial academic qualification.

This brings us to the work of R. C. Abraham. Although Abraham worked with four assistants, whom he called "collaborators" or "informants," yet, it is a difficult responsibility for a non-native person to author or even coordinate a dictionary. Abraham's collaborators (none of whom were co-authors), Mr. Samuel Winjobi, Mr. Duro Ogundiran (an attorney), Mr. Daniel Fagunwa (the famous Yoruba author popularly known as D. O. Fagunwa), and Mr. Lapade Obiesan (then a law student), who actually made the most contribution to the collections of the vocabulary ${ }^{20}$, were native speakers but hired as non-committing collaborators. This technically made the famous dictionary the sole work of a non-native speaker who, by his own admission, noted that "The present work is the outcome of three and a half years' research, interrupted by a short visit to South Africa." ${ }^{21}$ No doubt, a three and one-half year span of learning a language and its correspondent cultural nuances should be definitely less than sufficient for providing a viable dictionary of the language in question. The work of a dictionary could be a lifetime commitment; in fact, in some cases, it could be the work that spans several generations in its making. For example, it took 173 years to complete the famous Johnson's Dictionary of the English Language. ${ }^{22}$ If the Merriam-Webster model of authoring a dictionary is valid, and we have no data to validate or invalidate the claim, plus the scantiness of time of its completion, it suffices to agree that even the most published advanced dictionary in Yoruba language-in spite of the high caliber efforts put into it-still has its own limitations. The enduring legacy of R. C. Abraham's Dictionary of Modern Yoruba in its availability to scholars and learners of the Yoruba language and culture is that it has taught us that having something to work with is a better service than having none in the first instance.

Among the expected limitations of R. C. Abraham's Dictionary of Modern Yoruba are the following:

- Orthographical representations that are not in alignment with contemporary writing systems. Understandably, this was a text written many decades ago, and there have been many orthographical changes ever since.

20 Abraham, "Preface," p. iii

21 Abraham, ibid., iii

22 Hitchings, Henry (2005). Dr Johnson's Dictionary: The Extraordinary Story of the Book That Defined the World. London: John Murray. 
- Unorthodox sentence constructions. For example, on page 98, to exemplify and put in context the split verb "bà tì" Abraham writes: "Mo bàa tì láti sé" and translates the same as "It is beyond me."

- Misspellings of certain words.

- Words that are wrongly translated into the English language but which actually mean totally different ones.

- Dialectical entries that are not in conformity with Standard Yoruba.

- Chain referencing of lexical items that becomes confusing to users of the dictionary. While limited annotations are necessary in a dictionary, in some entries when overdone they could become superfluous.

- Unclear annotations or commentaries

- Tone marks that are incongruent with lexical items they denote

- Unintelligible entries. Take for example, in ẹ (both with low tones), Abraham writes, on page 171: (prefix occasionally used before verbroots to form nouns) $\underline{X}$ ẹeho $\underline{\mathrm{v}}$ èèho. For a native speaker, with or without knowledge of the linguistics of the language, this entry is completely meaningless. Take also, as another example, the word èèé (ayay-sheh), which Abraham enters on page 166: "(1) gleanings remaining after the crops have been gathered in (>șékú). (2) (a) ó pèèsé he gathered gleanings..." The two remain incomprehensible even to a competent user of the language.

All these should not come with any degree of surprise as a dictionary is inherently designed as a generic compass to word meanings. It is not a tool for pedagogical dissemination of knowledge, neither is it inherently designed to provide perfect information. In essence, a dictionary augments previous knowledge and only serves as a guide towards a clearer understanding of what the user already has an idea of what is being sought for.

We have identified some of these items not just to highlight the limitations of R. C. Abraham's Dictionary of Modern Yoruba, but to underscore the problem of creating a dictionary and to note that even the most comprehensive Yoruba dictionary could not be without its flaws. The problem is only exasperated by the non-native identity of the author and the fact that the work took a short span of research into the language and culture before the collection of the text. When compared, for example, to the time it took to create Johnson's Dictionary cited earlier, this is very much less researched, and the culture on which the dictionary is based less understood. In light of the prevailing need, however, it was necessary to have a working dictionary for the Yoruba language as of the time. Then, in the Yoruba cliché, having the diminutive bat in place of the giant one to offer to the gods is better than having none altogether. What Abraham's Dictionary did was to provide a working document 
to help advance the research efforts being triggered by the eagerness to do much with the Yoruba language and culture.

It is important to state here, however, that as will be demonstrated in what follows, even a dictionary executed by a native speaker who had both acquired intellectual and intuitive native skills comes with a host of its own problems. This underscores the fact that the profession of lexicography is intrinsically problematic.

It was against the backdrop of such limitations that the inspiration of I.O. Delano sprang out, leading to the ambitious connections of and research on what he called monosyllabic verbs. The work never got published in Nigeria, but was typeset and printed by the Ibadan University Press in 1969. This is the more readily available version, relatively speaking.

Among his motivation for working on this dictionary was the questionable literacy and peripheral knowledge of the people in the use of the Yoruba language. In his "Introduction to the Dictionary" Delano laments that:

In Yoruba, many people have a vague and inexact knowledge of many words, phrases and idioms, which have more than one meaning and can be used in more than one way, and which are needed for the expression of many ordinary notions and everyday concepts in common daily speech, but are frequently used inaccurately; there is also a total ignorance of many such words, phrases and idioms, which therefore are not used even when they are necessary. ${ }^{23}$

Furthermore, he berates the speech pattern that leans on code-shifting or code mixing in order to be able to successfully articulate self and communicate in or sustain conversations in the Yoruba language. This "dependency theory" explains why many abandon the use of Yoruba altogether and embrace the use of English instead. Delano further writes:

This insufficient understanding of the language causes many people to indulge in the speaking of English instead of Yoruba or to introduce English words, phrases, and idioms when speaking Yoruba; this destroys the beauty of the language and suggests that it is inadequate to bear the strains of every use. ${ }^{24}$

23 Because I worked on a manuscript on the dictionary being newly processed, there are no page references to Delano's work.

24 See footnote 22 . 
In his "Preface" to the seminal work, the then Director of the Institute of African Studies of the University of Ife, the late Research Professor Michael Crowther, commended Chief Isaac O. Delano as one who "has played a pioneering role in the study of the Yoruba language in the twentieth century." 25 In light of the pivotal work of the dictionary and many other contributions to Yoruba studies, this cannot but be true. The author of the dictionary, Chief Delano, made it clear that the work was not intended to be "a substitute for an ordinary dictionary; it deals specifically with verbs of one syllable which form an important structural feature of the language; it is intended for those who already have a fair knowledge of Yoruba but need help in speaking it correctly and writing it with taste and accuracy." ${ }^{26}$

\section{The Nature of Yoruba Verbs}

By virtue of the phonological and syntactic nature of the language, a verb in standard Yoruba does not have a vowel initial, although exceptions might be found in some dialects. Since verbs do not start with vowels, therefore, the two-volume work of Delano starts with the first consonant in the language, $/ \mathrm{b} /$, and the first among the first verbs is $b \dot{a}$, ending with the last of the verbs that starts with the /y/ initial, yum being the last in the entries.

Quite unlike that of Roy Clive Abraham, Delano's effort is more of the work of a philologist than that of a linguist, providing an exploration and exposition of an aspect of the language rather than a dictionary per se. As a grammatical category, verbs are core to Yoruba linguistics. By grammatical categories, we refer to what often generally includes parts of speech, syntactic variation and syntactic function. Verbs are at the core of Yoruba syntactic formation because if following by the matrix of transformative-generative grammar, a sentence in Yoruba-as in many languages for that matter-is simply given by:

$$
S=N p+V p \text { or } S=N p+V p+/-O b j
$$

Here, $S$ refers to the sentence, $N p$ is the noun phrase, $V p$ the verb phrase, while Obj stands for the object in a sentence, which is an optional occurrence in a complete Yoruba sentence. In essence, since this process is valid in the syntax of the Yoruba language, it is impossible to do without the verb or the verb phrase in the construction of any sentence in the language that would be construed as being complete.

25 See footnote 22 .

26 Same as above. 
The notion of a dictionary of Yoruba monosyllabic verbs in of itself is a bit confusing. This is because what Delano does in the work is more than isolating monosyllabic verbs and providing their meanings. He makes the verb the core lexis on which he builds several grammatical interpretations. In some cases, he takes homonymic verbs and translates them according to the different semantic nuances associated with the individual lexical items. In essence, for one interested in the phonological aspect of the work, the dictionary somehow accentuates the signification of toneme as a semantic marker in the language. Technically, "toneme" simply refers to the phonetic concept of distinguishing a phoneme by the simple phenomenon of tone. David Olmsted (1951) first identified this significant concept with reference to the Yoruba language. ${ }^{27}$ In what follows, we provide a fairly detailed example of his model of word-building that explores a variety of usages associated with a single monosyllabic verb phrase. Let's take a look at just the first segment of his entry of the verb bá:

"Bá- low"

1. to bend

a. arúgbó náà bà, the old man was bent with age.

$b \dot{a}$, té and wò:

these words mean to bend, but none can be used satisfactorily for another.

b. igi náà tè, the tree bends;

o tè igi náà, he bends the tree;

c. ọnàa wó, the road bends;

ọnà rẹ wọ́, he is not behaving properly

2. to plant on a specially prepared plant-bed with the intention to transplant Ȧgbẹ bà á, the farmer planted it on the plant-bed;

$b a ̀$ is used with words for all plants which are first planted on beds before re-planting: e.g. bakókò v. (bà + kókò), to plant cocoa on bed before transplanting

bẹpe v. (bà +ọpe); òpẹ, palm tree: barómbo; òrombó, orange

ba, gbin, fún, fón, lé or ló:

gbin, to plant on the farm prepared for the purpose;

ó gbin ișu; he planted yam;

ó gbin ìresì, he planted rice;

fún or fọn, lé or lọ gbin, to plant on the farm prepared for the purpose.

...

27 See David L. Olmsted (1951) “The Phonemes of Yoruba,” Word, 7:3, 245-249. 
O bèrù

O díji (dá + ìji)

Of'òyà (fò + àiyà/àyà)

The three sentences are near though not identical in meaning; bẹrù $\mathbf{v}$; is frequently used in all three types of sentences; but its popular meaning is equivalent to "to be afraid"; diji v. generally indicates some sense of cowardice in the person who was afraid and therefore expresses some emotional consciousness; fòiyà v. indicates fear due to feeling and sense of insecurity; ìfòiya n. (b) fífòiyà n.; l'áifòiyà v. (or $\mathrm{adv}$,) safety due to sense of security; the following from a popular hymn translation illustrates this: L'áifòyà l'ápa Jésù Safe in the arms of Jesus; Láifòiyà láiyà Rẹ Safe in His gentle breast. ${ }^{28}$

Twelve more pages of exposé on this single verb $b a$ would be devoted to the same lexical item in the dictionary. Needless to say, A Dictionary of Yoruba Monosyllabic Verbs is more than just an assemblage of monosyllabic words. Rather, it is a conglomeration of verb-related usages and the derivations of verbs in Yoruba grammar. Indeed, it could be seen as a complimentary addition to the author's popular A Modern Yoruba Grammar. ${ }^{29}$ Of course, it comes with its own package of problems, as will be examined momentarily.

\section{Significance of Verbs in Yoruba}

To appreciate the work of Delano, it would be important to see what others have done with the study of verbs in the language. As earlier noted, the verb, which is often called "òrò ìse" (literally, words of action) in the Yoruba metalingual phrase, is one of the most important lexical items in the Yoruba syntactic formation. Scholars like Ayo Bamgbose, Oladele Awobuluyi, Sope Oyelaran and many more, have devoted scholarly attention to the subject. Oladele Awobuluyi and Sope Oyelaran (2017) call attention to the rules that govern the various use of verbs in their syntactic environments. ${ }^{30}$ Oyelaran has particularly given credence to the contextual significance of this grammatical category in the language by taking on various works that have muddled up the function of verbs through fuzzy classifications. Take, for example, Oyelaran (and partly Awobuluyi)'s works on the sub-classification of the Yoruba verbs, which constitute the main thrust of the article of Adewole (2018).

28 See footnote 22.

29 See I. O. Delano, A Modern Yoruba Grammar. Thomas Nelson and Sons Ltd., 1965.

30 See O. Awobuluyi and O. Oyelaran, İléwọ İkọwé Yorùbá Òde-Òní. Ilorin: Kwara State University Press, 2017, p.27. 
In this article, Adewole shows how with examples Oyelaran systematically demonstrates the difficulty and apparent weaknesses inherent in the method of classification of words based on meaning in the language, as a class of grammarians have done. Citing examples, Oyelaran points out the contradictions inherent in such positioning. Bamgbose's "Introduction" to his A Short Yoruba Grammar is even more explicit about this problem. After pointing out a series of exceptions to the old grammarian definitions of grammatical categories, he notes that:

What is wrong with a 'meaning' criterion, therefore, is that it is not precise. It usually includes more than it is intended to cover and, at the same time, it sometimes excludes some of the items intended to be included. ${ }^{31}$

Phonological variance, for example is another criterion that Oyelaran points out as a parameter that has been used for lexical classifications. The erroneous assumption in this position, according to Oyelaran, is that all Yoruba verbs are monosyllabic. However, he further argues that such an assumption precludes the inclusion of multisyllabic words like wàhálà, gẹlẹtẹ, or even words like láifí, gàrí, etc., each of which in context could play the role of a verb as they could be seen as nouns. For example:

\section{Lágbájá láifí mi}

(X insults/abuses me verbally)

Șé iwọ l’ò ń gàríi mi ni?

(Are you the one feeding me, after all?)

"Morphological criterion, in Oyelaran's (1976:2) opinion, cannot also be used to classify Yoruba words into categories especially as Yoruba does not have inflectional morphemes to mark gender, tense and case ..." 32

Contextual usage, that is, the function of a word within a syntactic frame, seems to be the criterion recognizable as a viable parameter for determining the classification and denotation of words in the language.

Awobuluyi's position is technically in alignment with that of Oyelaran in the classification of words in Yoruba. In other words, a word is an arbitrary concept until it is contextualized, although the ensuing sub-classification of verbs into thirteen different categories contradicts Awobuluyi's claim of the fluidity of words outside contexts. His classification of verbs, for example, are:

31 See Bamgbose, 1967, p1.

32 See Adewole, Lawrence O. "Oyelaran on the Subclassification of the Yorùbá Verb. Research in Yoruba Language and Literature, No. 13. 2018: 162. 
serial verbs, splitting verbs, echoing verbs, complex verbs, adjectivisable verbs, nominal assimilating verbs, particle selecting verbs, report verbs, impersonal verbs, causative verbs, symmetrical verbs, interrogative verbs, and imperative verbs. Adewole points out that much of Awobuluyi's sub-classifications are based on the syntactic behavior of the verbs, while the others are based on morphological/derivational and phonological criteria. Also, the fact that some verbs could actually fit snugly into more than a single category defeats the essence of the said categorization. In all, one could see that the positions of a word in the Yoruba language has much to do with its value in the grammatical context. One aspect that none of the scholars pay serious attention to in the grammar of the language is the roles of the prosodic features. In essence, even within the same contexts, words, or even the whole sentence, can change meaning in Yoruba speech purely on the basis of how they are phonetically articulated. This semiotic phenomenon is not the focus of the current work.

Bamgbose's work on verbs is also noticeable. In his A Short Yoruba Grammar (HEB, 1967), a booklet that has become a classic to researchers of the Yoruba language, Bamgbose dedicates a whole chapter to what he calls "The Verbal Group." He describes the verbal group as "a word or group of words which can stand as the predicate of a clause ... The group of words is always a combination of verbs or a combination of verb(s) objects (s) ..."33 Bamgbose then goes ahead to identify three classes of verbs, which are the following:

(i) Those that must always be followed by another verb whenever they occur in a verbal group, e.g. ti in mo ti lọ "I have gone." These are called preverbs.

(ii) Those that can occur independently in the verbal group, e.g. wá in ó wá "he came." These are called free verbs.

(iii) Those that must be preceded by another verb whenever they occur in the verbal group, e.g. sí in mo lo sí oko "I went to the farm." These are called post verbs.

Each of Bamgbose's verbal groups comes with further sub-classifications. For instance, the preverbs include verbal particles, restricted preverbs, unrestricted preverbs, and negators. The same goes with free verbs and post verbs with their own different sub-classifications.

Bamgbose is able to further identify two tenses: simple, and perfective; both of which could come as positive or negative. These could be marked by five features: future, conditional past, continuous, habitual, and unmarked. There are many other forms of Yoruba verbs. Split verbs, for example, are the

33 Bamgbose, Ayo. A Short Yoruba Grammar, Heinemann, 1967. 
kind that could be broken into two morphemes with the object set between the morphemes. For example, consider this question:

Èwo ni lágbájá paje?

(Which one did somebody butcher or slaughter for consumption)?

The verb in this context is paje (butcher or slaughter for consumption). The response could be, for example, Ewuré ni o paje (It was the goat he slaughtered for consumption). This could become a split verb in a sentence such as:

Mo pa ewúréjẹ

(I slaughtered and ate the goat)

In yet another example, consider this sentence:

Ișé ni mo pati

(It is/was work that I abandoned)

The verb in this context is pati (abandon). The response could be, for example, Ișé ni mo pati (It is work that I abandoned). This could become a split verb in a sentence such as:

Mo pa ișé ti

(I abandoned the work)

Examples abound in this category of verbs in the Yoruba language. There are many aspects of grammar that are related to verbs. Tenses, for example, are integral parts of the verbal groups in Yoruba, to which several authors have dedicated a significant part of their works.

\section{Uniqueness of Delano's Dictionary}

What the works of these Yoruba linguists underscore is the complex nature of verbs in the language. Therefore, an attempt on the compilation of verbs-monosyllabic ones in the language for that matter-was a challenging task for Delano.

Delano's work is based on the 1966 Yoruba orthography because, as of the time of the writing, according to the author, even though the system had not been adopted by the government, the recommendation of the orthographic committee represented "the views of the leading Yoruba authors, grammarians, linguists, and teachers who formed the Committee." ${ }^{34}$

While this work of Delano represents a timeless documentation among the dictionaries in the language, there is no doubt that like any standard

34 See footnote 22. 
dictionary, more needs to be done by way of consistently revising it. Reorganizing the individual lexical items to reflect, for example, a variety of verbs in the language, not just the monosyllabic ones, would be in order. Correct tonemic representation of words, which would take into consideration the range of meanings that are possible within a combination of alphabets in the language, would help the users of the dictionary. Take for example:

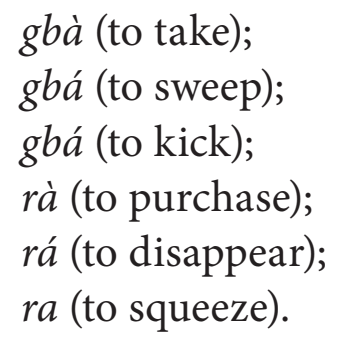

While Delano tries to do this in some of his entries to some extent, the tendency to confuse some of the words together and a lack of consistent chronological arrangements of those admitted items into the repertoire of vocabularies further makes aspects of the text hard to comprehend.

\section{Limitations}

Even with the best intentions, every human effort must face its own limitations. This is particularly so in scholarly works. Research reports often end with the researcher highlighting a list of limitations faced in the process of carrying out the research and writing the report. The nature of dictionary writing is even more prone to such limitations, and as noted in the works of Crowther and R. C. Abraham, they are expected. Thus, what we found to be weaknesses or imperfections in Delano's work are not peculiar to Delano. They only suggest that the work, like any standard dictionary, as we noted earlier, deserves to be revised as often as possible. As a matter of fact, one of the unique points of Delano's work is in the fact that there has not been a more comprehensive assemblage of Yoruba monosyllabic verbs since its publication. Continuing to work on it by other lexicographers of the language would be a great addition to Yoruba scholarship. In what follows, then, we highlight a few of the observed limitations.

Unilateral Effort of the Author: Delano's work seems to be a solo effort. It is not altogether impossible to be the sole author of a dictionary, but it would pose more challenges than if the process were to be a joint effort. Unlike R. C. Abraham, whose work identifies the cooperation of a small group of "collaborators" or "informants," I. O. Delano's dictionary was done with no known 
collaborators. It is, therefore, lacking in what the Yoruba call ogbọ́n olọgbọ́n (the wisdom of others), since in the context of the people's rhetoric, expressions abound that celebrate the sacrosanctity, optimism and possible successes emanating from cooperative actions. This does not diminish the effect of the Dictionary's usefulness to researchers, learners and scholars of the language; it only points to the missing strength of "value added" prospects of multiple voices, impressions and opinions that could build a lasting legacy of a viable dictionary. Were the work to be revised, such collaboration would be in order.

Obsolete Orthography: Understandably, the orthography of Delano is archaic. Further complicated by the use of dialect, the 1966 orthography which the author uses is apparently difficult to comprehend. It is also easy to find inconsistencies in the author's use of the said orthography.

Scantiness of Entries: The identified "monosyllabic verbs" in the entries are obviously limited. Altogether, there are only 286 verbs identified, even though with the elongated annotations, more usages of those verbs and verb phrases are included. The Dictionary also brings into the mix some borrowed words from foreign languages, especially the English language. Certainly (and logically, too), the number of monosyllabic verbs in the Yoruba language should be more than what we find in the book. Indeed, one would expect the work of a standard dictionary to have more entries of words and phrases than the number contained in the current work of I. O. Delano. However, in light of the solo effort already highlighted above, for I. O. Delano, this limitation should be understandable.

Obscure Entries: There are many unclear entries, too numerous to exemplify. For example, tone-marks do not correspond to their semantic equivalents in some cases. Furthermore, sometimes the English translations of sentences do not agree with their Yoruba counterparts. It is possible that some of the confusions may be an attribute of the dialectical impediment, since like most dialects in Yoruba, except for Oyo (of which the standard form of Yoruba orthography is its coine), the Egba dialect, on which Delano leans on occasions, does not align with the standard Yoruba orthography, and thus the meanings often may not add up.

Peculiarity of the Dictionary: As earlier noted, Delano's Yoruba "dictionary" is a departure from the promise of a traditional dictionary, as it does not conform with the known models of dictionaries. For one thing, in many cases, it does not give a systematic arrangement of words by their meaning. Instead, it discusses and elaborates on lexical items determined to be monosyllabic 
words. For this work to occupy the standard status of a modern dictionary, it would be in order to broaden the horizon of it beyond monosyllabic verbs. The work should be a comprehensive assemblage of Yoruba words, spreading into all grammatical categories, phrases and idiomatic expressions, among others in the language. An all-encompassing dictionary would help users of the language more than a specialized form like this one. Otherwise, Delano's work could at the very best be construed as an annotated glossary of monosyllabic verbs, or it could fit the model of an aspect of an encyclopedia on the language. Yet, it is the so far the best (and probably the only) known work of monosyllabic verbs assemblage in the vast history of Yoruba scholarship.

\section{Reference}

Adewole, Lawrence O. "Oyelaran on the Subclassification of the Yoruba Verbs," Research in Yoruba Language and Literature, No. 13 (2017): 160-169. Alhaisoni, Eid. "EFL Teachers' and Students' Perceptions of Dictionary Use and Preferences," International Journal of Linguistics Vol. 8, No. 6 (2016): 31- 52.

Armstrong, Robert G. 'Roy Clive Abraham, 1890-1963', Journal of West African Languages, 1/1 (1964), 49-53.

Armstrong, Robert G. "Dictionary of Modern Yoruba By Abraham Roy C." London: University of London Press, 1958. Pp. xli + 776, ill. 35s. - Volume 29 (1).

Awobuluyi, Oladele and Olasope Oyelaran, Ilewo Ikowe Yoruba Ode-Oni. Ilorin: Kwara State University Press, 2017.

Bamgbose, Ayo. A Short Yoruba Grammar. Ibadan: Heinemann Educational Books (Nigeria) Ltd., 1967.

Bergenholt, Henning. "What is a Dictionary?" Lexikos 22 (2012): 20-30.

Carstens, Adelia. "Language Teaching and Dictionary Use: An Overview." Lexikos 5 (1995): 105-116.

Cortés, Ximena. "Using the Dictionary for Improving Adolescents' Reading Comprehension of Short Scientific Texts." PROFILE Vol. 15, No. 2 (2013): 11-33.

Delano, Isaac O. A Modern Yoruba Grammar. London, UK \& Lagos, Nigeria: Thomas Nelson and Sons Ltd. 1965.

Fageeh, Abdulaziz Ibraheem. "Effects of Using the Online Dictionary for Etymological Analysis on Vocabulary Development in EFL College Students." Theory and Practice in Language Studies Vol. 4, No. 5 (2014): 883-890.

P. E. H. Hair, "A bibliography of R. C. Abraham - linguist and lexicographer," Journal of West African Languages, 2/1 (1965), 63-6. 
Ilson, Robert. "Introduction." In Dictionaries, Lexicography and Language Learning," edited by Robert Ilson, 1-6. Oxford: Pergamon Press Ltd., 1985. Jenpattarakul, Win. "Optimizing the Advantages of Monolingual Dictionary Utilization by Thai EFL Students," Mediterranean Journal of Social Sciences Vol. 3 (11) (2012): 1465-152.

Nation, Paul. Teaching Vocabulary (Strategies and Techniques). Boston: Heinie, 2008.

Olmsted, David L. "The Phonemes of Yoruba," WORD, Vol. 7 (3) (1951): 245-249.

Soyinka, Wole. "He came, He Saw ..." in Wole Ogundele's Gone to Join Obatala: Tributes on Ulli Beier, Osogbo: Kingsmann Graffix, 2012, p. 57. 